\title{
Artigos
}

Ligia de Carvalho Abões Vercelli ${ }^{1}$

\section{EDUCAÇÃO INFANTIL: DISSERTAÇÕES REALIZADAS EM UM PROGRAMA DE MESTRADO PROFISSIONAL (2013-2019)}

\author{
CHILD EDUCATION: DISSERTATIONS DONE IN A PROFESSIONAL \\ MASTER PROGRAM (2013-2019)
}

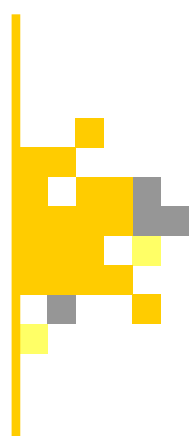

\section{RESUMO:}

Esse artigo tem por objetivo apresentar um levantamento das dissertações realizadas sobre e na Educação Infantil em um Programa de Mestrado Profissional de uma universidade privada localizada na cidade de São Paulo, no período de novembro de 2013 a dezembro de 2019. Nossos questionamentos são os seguintes: Quantas pesquisas foram realizadas desde a aprovação desse Programa de Mestrado Profissional? Quantos trabalhos discutiram a Educação Infantil? Quais foram as temáticas abordadas? $\mathrm{O}$ que os autores nos dizem sobre os resultados obtidos? As pesquisas indicaram que as escolas da infância ainda se utilizam, ora de propostas assistencialistas ora de propostas preparatórias para o ensino fundamental, portanto, não vislumbram as especificidades da infância. Além disso, os resultados reafirmaram a falha na formação inicial dos/as professores/ as e o papel fundamental da equipe gestora na condução da formação em serviço.

Palavras-chave: Mestrado profissional. Educação Infantil. Produções acadêmicas. Infância.

\section{ABSTRACT:}

This article aims to present a survey of the dissertations carried out on and in early childhood education in a Master's Program of a private university located in the city of São Paulo, in the period from november 2013 to december 2019. Our questions are the following: How many surveys have been conducted since the approval of this Professional Master's Program? How many papers discussed early childhood education? What were the topics addressed? What do the authors of the area tell us about the results obtained? The researches indicate that the schools of the childhood are still used, sometimes of proposals of assistance or of proposals preparatory to the elementary school, therefore, they do not glimpse the specificities of childhood. In addition, the results reaffirmed the failure of the initial training of the teachers and the fundamental role of the management team in conducting inservice training.

Keywords: Professional master's. Child education. Academic productions. Childhood.

\section{INTRODUÇÃO}

Esse artigo tem por objetivo apresentar um levantamento das dissertações realizadas sobre e na Educação Infantil em um Programa de Mestrado Profissional em Educação de uma universidade privada localizada na cidade de São Paulo, no período de novembro de 2013 a dezembro de 2019.

Tal Programa, aprovado pela Coordenação de Aperfeiçoamento de Pessoal de Nível
Superior (Capes) no final de 2011 com nota 3, iniciou as atividades em fevereiro de 2012, e na primeira avaliação quadrienal de 2017 foi avaliado com nota 5 pela Comissão de Área (CA) e nota 4 pela Capes, portanto, alcançou os objetivos propostos à época da aprovação.

Para obterem o título de mestre em educação, os mestrandos realizam, em sua maioria, pes-

\footnotetext{
${ }^{1}$ Doutora e Mestra pelo Programa de Pós-Graduação em Educação da Universidade Nove de Julho (PPGE/Uninove). vercelli.ligia@gmail.com (iD) http://orcid.org/0000-0002-1381-464X
} 
quisas-intervenção com foco na própria prática. São professores/as, coordenadores/as pedagógicos/as e diretores/as que, em horários de reunião pedagógica, discutem e analisam seus objetos de estudo com os demais profissionais da escola, a fim de que eles/as possam, posteriormente, ressignificar suas práticas.

Nossos questionamentos para a discussão deste artigo são os seguintes: Quantas pesquisas foram realizadas desde a aprovação desse Programa de Mestrado Profissional? Quantos trabalhos discutiram a Educação Infantil? Quais foram as temáticas abordadas? O que revelam as pesquisas?

Em levantamento realizado no site da instituição, verificamos que, desde a abertura do Programa, isto é, de 2013 até o mês de dezembro de 2019, foram defendidas 142 dissertações, sendo duas em 2013; vinte e sete em 2014; vinte e três em 2015; vinte e sete em 2016; vinte e oito em 2017; onze em 2018; catorze em 2019 e onze até julho de 2020. Destas, 24 pesquisas discutiram a Educação Infantil: três em 2014; seis em 2015; duas em 2016; quatro em 2017; três em 2018; seis em 2019 e nenhuma até julho de 2020 , portanto, $16,9 \%$ do total, o que significa um número inexpressivo de pesquisas sobre essa etapa da educação básica.

Porém o número de trabalhos defendidos será aumentado, uma vez que o site da universidade aponta como previstas, em edital, duas qualificações e duas defesas sobre e na Educação Infantil, ainda no segundo semestre de 2020. Além disso, podemos visualizar que existem 13 trabalhos em andamento sobre essa primeira etapa da educação básica. Destes, alguns ainda poderão ser qualificados em 2020.

A partir de 2015, com a consolidação do nosso grupo de pesquisa, verificamos que o número de profissionais interessados em discutir políticas públicas, formação de professores e práticas pedagógicas e de gestão sobre essa etapa de ensino têm aumentado; assim, muitos integrantes participam do processo seletivo para ingresso no Mestrado Profissional da instituição. Nossa hipótese é que tal procura esteja relacionada também aos colóquios que o grupo realiza semestralmente des- de 2014, pelos convites que recebemos para palestrar em deferentes diretorias de ensino, pelas aulas que ministramos nos cursos de graduação, dando visibilidade ao nosso trabalho, e pelas publicações de livros realizadas anualmente.

Este artigo está dividido em duas partes, a saber: a) um breve panorama do Programa de Mestrado da referida universidade; b) apresentação e análise das 24 dissertações defendidas até julho de 2020.

\section{BREVE PANORAMA DO PROGRAMA DE MESTRADO PROFISSIONAL PES- QUISADO}

Antes de apresentarmos o panorama do Programa de Mestrado Profissional da universidade pesquisada, vale lembrar que essa modalidade é recente no curso stricto sensu. 0 primeiro Programa na área educacional, Mestrado Profissional em Gestão e Avaliação da Educação Pública, surgiu no Brasil em 1999, na Universidade Federal de Juiz de Fora (UFJF), portanto, há 19 anos, e vem ganhando espaço desde então. Segundo dados da Plataforma Sucupira até agosto de 2020, o Brasil conta com 50 Programas de MP, sendo: seis na Bahia, um no Distrito Federal, três no Maranhão, seis em Minas Gerais, um no Mato Grosso do Sul, dois na Paraíba, dois no Paraná, quatro em Pernambuco, cinco no Rio Grande do Sul, dois em Santa Catarina, treze em São Paulo, um no Tocantins, um no Rio Grande do Norte, dois no Ceará, um no Espírito Santo.

Em 23 de março de 2017, a Portaria n. 389, do Ministério da Educação (MEC), institui, no âmbito da pós-graduação stricto sensu, a modalidade de Doutorado Profissional (DP) inexistente até o momento no Sistema Nacional de Pós-Graduação. Atualmente, o Brasil conta com dois Programas de DP, sendo um no Paraná e um em Rondônia. Ambos os Programas, segundo a referida portaria, têm o objetivo de:

[...] capacitar profissionais qualificados para o exercício da prática profissional avançada e 
transformadora de procedimentos, visando atender demandas sociais, organizacionais ou profissionais e do mercado de trabalho; de transferir conhecimento para a sociedade, atendendo demandas específicas e de arranjos produtivos com vistas ao desenvolvimento nacional, regional ou local; de promover a articulação integrada da formação profissional com entidades demandantes de naturezas diversas, visando melhorar a eficácia e a eficiência das organizações públicas e privadas por meio da solução de problemas e geração e aplicação de processos de inovação apropriados; além de contribuir para agregar competitividade e aumentar a produtividade em empresas, organizações públicas e privadas (BRASIL, 2017, n.p.).

Os pesquisadores que cursam o Mestrado Profissional buscam atender demandas sociais e profissionais emergentes, na maioria das vezes, de suas realidades; portanto, pesquisam a própria prática e/ou situações da escola na qual trabalham para que possam oferecer uma resposta às questões que se impõem na realidade educacional. $\mathrm{Na}$ nossa universidade, os/as pesquisadores/as utilizam-se da pesquisa-intervenção como metodologia. Segundo Damiani (2012, p. 3);

[...] denominam-se intervenções as interferências (mudanças inovações), propositadamente realizadas, por professores/pesquisadores, em suas práticas pedagógicas. Tais interferências são planejadas e implementadas com base em um determinado referencial teórico e objetivam promover avanços, melhoria nessas práticas, além de pôr à prova tal referencial, contribuindo para o avanço do conhecimento sobre os processos de ensino/ aprendizagem neles envolvidos [...].

Gabre (2012, p. 4) ressalta que, na pesquisaintervenção, os sujeitos podem ser "[...] tanto o pesquisador quanto os pesquisados e ambos têm um papel ativo no processo da pesquisa". Isso significa que o professor pesquisador pode intervir e propor ações sobre o contexto no qual está inserido a fim de objetivar transformação na prática pedagógica dos/as professores/as; portanto, a reflexão sobre a prática é o ponto de partida.

A autora, citando Moreira $(2008)^{2}$, aponta dois princípios que regem a pesquisa-intervenção.
São eles: a) a consideração das realidades sociais e cotidianas; b) o compromisso ético e político da produção de práticas inovadoras. Pautando-se nesses dois princípios, Moreira (2008 apud GABRE, 2012 , p. 2-3) destaca cinco características da pesquisa-intervenção, a saber:

1.Deve acontecer dentro do contexto pesquisado; 2.É desencadeada pela demanda, contribuindo na solução de problemas;

3.0 pesquisador atua como mediador que articula, organiza encontros, sistematiza as vozes e os saberes produzidos pelos sujeitos envolvidos na pesquisa, agindo num processo de escuta ativa; 4.Interação entre o pesquisador e os sujeitos da pesquisa;

5.As experiências cotidianas e práticas do coletivo, sistematizadas, permitem descobertas e elaborações teórico metodológicas.

Vale ressaltar que dos 24 estudos sobre e na Educação Infantil realizados na instituição pesquisada, 21 se utilizaram da pesquisa-intervenção, portanto, os pesquisadores consideraram as realidades nas quais as escolas estavam inseridas e honraram com o compromisso ético estabelecido com a instituição e com os profissionais sujeitos da pesquisa. As cinco características citadas também se fazem presentes nos trabalhos.

O panorama apresentado referente ao Programa de Mestrado Profissional em Educação da universidade em foco, retirado do site da instituição, revela que os pesquisadores buscam desenvolver pesquisas sobre situações que concernem às demandas e problemas do dia a dia escolar, especialmente aqueles relacionados à gestão pedagógica, aos recursos educacionais e às práticas de ensino e aprendizagem, objetivando efetivar o diálogo entre teoria e prática, a fim de não dicotomizar a pesquisa das questões pedagógicas.

Desde sua aprovação, em 2011, a área de concentração na formação do Programa estruturou-se em duas linhas de pesquisa e de intervenção. Uma das linhas realiza as investigações sobre concepções e ações que incidem na gestão educacional e escolar, envolvendo sistemas e unidades educacionais da escola básica. A segunda linha de-

\footnotetext{
2 Obra referenciada por Gabre: MOREIRA, M. I. C. Pesquisa-intervenção: especificidades e aspectos da interação entre pesquisadores e sujeitos da pesquisa. In: CASTRO, L. R de; BESSET, V. L. (Org.). Pesquisa-intervenção na infância e juventude. Rio de Janeiro: NAU, 2008.
} 
senvolve pesquisas a respeito de temáticas relacionadas a metodologias de aprendizagem e ensino de todos os ciclos e etapas da educação básica.

Os referenciais teóricos que fundamentam as pesquisas das duas linhas estão voltados aos autores da pedagogia crítica, psicologia sóciohistórica e teoria crítica.

\section{AS TEMÁTICAS E AS ANÁLISES DAS 24. DISSERTAÇÕES DEFENDIDAS DE FEVEREIRO DE 2014 A DEZEMBRO DE 2019: O QUE OS ESTUDOS APONTAM?}

Apresentamos a seguir as temáticas e os resultados das dissertações defendidas sobre e na Educação Infantil no período temporal de fevereiro de 2014 (ano no qual foi defendida a primeira dissertação sobre essa etapa de ensino) a dezembro de 2019 (uma vez que não há pesquisas defendidas desta etapa de ensino em 2020, no site da instituição) do Programa de Mestrado Profissional pesquisado. Vale apontar que todas as pesquisas foram realizadas em apenas uma instituição de ensino de diferentes redes da grande São Paulo e apenas 4 não são do tipo intervenção.

As temáticas referentes às práticas pedagógicas na Educação Infantil versaram sobre: docência; concepção de criança; registro como instrumento de reflexão na formação docente; leitura e escrita, educação para as relações étnico-raciais; espaços lúdicos como elementos formadores; saberes e fazeres docentes em artes, relação entre creche, pais e comunidade; qualidade das práticas educativas na creche; formação continuada dos professores da rede direta e parceira da cidade de São Paulo; daltonismo na Educação Infantil; afetividade entre profissionais da educação, o uso dos objetos transicionais no período de adaptação.

Os estudos referentes às dificuldades encontradas no início e no decorrer da docência estão associadas a diferentes causas, a saber: dicotomia existente entre teoria e prática no curso de formação de professores; a legislações atuais sugerem, de forma genérica, o papel do profissional que irá trabalhar diante da criança de até 5 anos de idade; poucas disciplinas abordavam a Educação Infantil no curso de formação, portanto, insuficiente para discutir questões tão complexas voltadas às crianças pequenas, ao papel do professor etc.

Diante destes resultados, percebemos o quanto a formação inicial é deficitária. Nossa preocupação quanto a isso é que esses profissionais estão diante de crianças pequenas e que necessitam de todo o conhecimento para os pequenos possam se desenvolver nos aspectos cognitivo, afetivo, social e cultural. A dicotomia teoria/prática apontada nas pesquisas revela o quanto o curso de Pedagogia é teórico, dessa forma, o professor não sabe como proceder diante das crianças.

No que se refere à concepção de criança, as pesquisas indicam que as professoras, em sua maioria, têm uma prática intuitiva, pouco fundamentada em teorias da educação, tomando como base experiências vivenciadas no cotidiano; realizam atividades que deixam de potencializar as oportunidades de aprendizagens significativas para as crianças; além de que a observação que as professoras fazem com relação à criança não ocorre no sentido de mediar e intervir, estando meramente atentas a comportamentos.

Os resultados deste estudo vêm ao encontro do que dissemos em relação à pesquisa anterior. Acrescentamos que o olhar adultocêntrico é o que predomina e que o comportamento das crianças deve seguir a lógica do ensino fundamental, ou seja, quietas, sem pronunciar suas palavras, com seus corpos dóceis, bem como sinaliza Foucault (2009).

O estudo realizado sobre leitura e escrita revela que, numa determinada escola, as professoras têm se distanciado das práticas preparatórias para a alfabetização, buscam incluir práticas diárias de leitura, atividades em que se propõem às crianças lerem e escreverem palavras e textos de seus respectivos contextos, porém há muita dificuldade por parte das professoras de pré-escola em aceitar esse novo modelo, uma vez que para elas a criança deveria chegar alfabetizada no primeiro ano do ensino fundamental.

Esse estudo revelou o quanto a formação continuada sobre leitura e escrita na Educação Infantil foi fundamental para que as professoras tivessem outro olhar sobre a criança. Elas perceberam que partindo da leitura do mundo e do "saber 
da experiência feito", como nos aponta Freire (1987), é possível uma prática alfabetizadora ainda nessa etapa da educação básica. Afinal, a criança está inserida em uma sociedade letrada que apresenta a ela as letras, os numerais e as palavras.

A pesquisa sobre o registro aponta que esse instrumento contribui para o processo de reflexão sobre a prática, contudo as condições de trabalho e a burocratização impediram que as professoras registrassem as ações de forma crítica e reflexiva, assim, a socialização dos registros feitos pelas docentes com a colaboração da coordenadora contribuiu com o processo de reflexão coletiva.

Esta pesquisa também apontou o papel relevante da formação continuada e da potência dos registros para uma transformação efetiva do cotidiano. O mais importante foi as professoras perceberem que muitas das dificuldades que enfrentam está no coletivo e que as discussões pautadas nos registros efetuados descortinaram as angústias e ansiedades, assim como revelaram as alegrias dos momentos cotidianos.

O trabalho a respeito das concepções das professoras sobre relações étnico-raciais na Educação Infantil revela que por meio da intervenção realizada pelo autor, tais concepções foram se modificando, saindo do senso comum para uma compreensão mais elaborada, à medida que nos encontros de formação propostos, as observações e devolutivas eram feitas momentaneamente, apontando que a formação continuada de docentes sobre essa temática representa um caminho profícuo para incorporá-la nas reflexões e práticas docentes.

Novamente nos deparamos com a potência da formação continuada. Não podemos deixar de apontar que o papel do gestor/pesquisador ou do professor/pesquisador é de extrema importância, pois no decorrer do estudo ele mesmo percebe fragilidades e busca minimizá-las. No caso desta escola, as questões étnico-raciais eram camufladas. Vele lembrar que tal conteúdo também é pouco abordado nos cursos de formação.

A pesquisa sobre os espaços lúdicos revelou que as professoras tiveram um maior envolvimento no trabalho pedagógico com as crianças pequenas, perceberam o quanto suas posturas foram fundamentais no processo de desenvolvimento dos pe- quenos, contribuíram mais umas com as outras nos momentos de rodas de conversa, disponibilizaramse, ainda mais, na criação de estratégias apropriadas à faixa etária das crianças, reconheceram o potencial delas como contribuintes para o planejamento e construtores do próprio conhecimento, bem como a importância dos espaços lúdicos da creche como elementos formadores.

Nesta pesquisa, a coordenadora/pesquisadora esteve junto com as professoras no dia a dia reformulando os espaços lúdicos sempre em constante formação nos horários de reunião pedagógica, levando-as a perceber a potência dos bebês e das crianças pequenas, uma vez que muitas sugestões de mudança partiram deles.

O estudo sobre as práticas e discursos das professoras a respeito da arte revela que o trabaIho pedagógico decorre por meio de reflexos dos percursos pessoais e profissionais das professoras. A consciência da fragilidade em suas formações foi sinalizada pelas docentes, sobretudo quando requisitavam formação permanente. As práticas pedagógicas das professoras se caracterizavam por atividades isoladas que foram reproduzidas para todos as crianças, com controle centrado na figura das professoras.

Outra vez estamos diante de questionamentos quanto à formação inicial e continuada. É importante salientar que a requisição, por parte das professoras, de formação permanente, colocaas na zona de conforto. A formação deve ser dialógica, com preparação de todas para que haja mobilização para a mudança.

Dois estudos discutiram a relação família, escola e comunidade. Um deles explicitou como foi desenvolvido um projeto com a participação das crianças, dos pais e da comunidade e o outro teve a reunião de pais como foco. No primeiro, verificamos que o trabalho com projetos estreitou os laços entre família, comunidade e creche, contribuindo para a aprendizagem de todos, permitiu um trabalho interdisciplinar com as crianças, familiares e líder comunitário, levando-os a perceber que a creche não se limita a cuidar da criança, mas, principalmente, educar para a vida em sociedade. $O$ segundo estudo revelou que as reuniões de pais podem constituir momentos de troca entre a escola e as famílias. Os pais revelaram a impor- 
tância da participação e da contribuição ativa dos familiares, tanto no aprimoramento das reuniões, quanto no trabalho pedagógico, elaborado junto às crianças.

Estes estudos nos obrigam a dizer que não é possível falar em Educação Infantil sem recorrer à família. Tratam-se de duas instituições que têm de caminhar juntas para o bem-estar da criança. Quando os pais ficam a par do trabalho realizado pela equipe escolar, eles valorizam mais a escola, pois percebem o quanto as atividades objetivam a aprendizagem e o desenvolvimentos dos pequenos.

A pesquisa sobre o uso dos objetos transicionais no período de adaptação aponta que as professoras possibilitaram que as crianças fizessem uso durante o período de adaptação, que, no momento do sono, elas adormeceram antes das demais crianças, acalmaram-se mais rapidamente, além de se adaptarem com maior facilidade à rotina da instituição, demonstrando segurança e conforto.

Lembramos que os objetos transicionais (chupeta, paninho, brinquedos, bichos de pelúcia etc.;) realizam a transição das crianças, das pessoas e espaços familiares para pessoas desconhecidas em espaços institucionais. $O$ fato de a criança querer fazer uso de um desses objetos indica que ela precisa estar emocionalmente apoiada em figuras conhecidas até que crie o vínculo com as professoras e o ambiente escolar.

O estudo sobre as relações entre profissionais da educação aponta que a afetividade, na instituição estudada, é pouco reconhecida nas relações entre professoras e coordenadora, fato este que traz implicações no desenvolvimento do trabalho conjunto da unidade escolar. Segundo as professoras, a coordenação pedagógica funciona como um suporte para todo o trabalho desenvolvido na escola e, por isso, enfatizam a importância do profissional que assume esse papel, o qual deve dialogar com o grupo sobre as diferentes ideias na articulação de um projeto educacional. Para isso, entendem que o ouvir, olhar e perceber o outro é papel do gestor.

As questões relativas à afetividade ainda são pouco discutidas e entendidas em nossa sociedade. A gestão tem papel fundamental, pois ao escutar as professoras e seus anseios, o vínculo de confiança se estabelece, sendo possível um trabaIho transformador no contexto escolar.

A pesquisa sobre o daltonismo na Educação Infantil revela que os educadores reconhecem a importância do uso de instrumentos rastreadores como ferramentas de sondagem de crianças daltônicas, bem como, a necessidade de formação para a compreensão do daltonismo. Faz-se necessário acolher e incluir as crianças nos planejamentos, nas atividades, e nos contextos de forma integral.

Tratamos até o momento da única pesquisa sobre inclusão. A autora se baseou na história do filho daltônico, hoje adulto, que, desde a Educação Infantil nunca foi compreendido em sua deficiência. Utilizamos o termo deficiência, pois a autora assim o coloca e luta para que o daltonismo seja incluído como uma deficiência para que as professoras possam realizar um trabalho diferenciado com essas crianças.

O estudo sobre a construção do número em atividades contidas em um livro de matemática revela que o livro traz preocupações em trabaIhar atividades práticas com as crianças e não somente como registros de atividades. Contribui auxiliando os/as professores/as nos pressupostos do Referencial Curricular Nacional para a Educação Infantil (RCNEI), embora muitas atividades partam do/a docente e não da criança como protagonista. O lúdico se faz presente no livro, auxiliando no desenvolvimento do raciocínio lógicomatemático e favorecendo a construção do número uma vez que contém atividades práticas, contudo algumas são de difícil execução para a faixa etária de 5 anos.

Vale lembrar, como consta na dissertação, que a autora é contra o uso de livro didático na Educação Infantil, porém, por coordenar uma escola privada que obriga a utilização para crianças de 4 e 5 anos, ela sentiu necessidade de fazer uma análise mais apurada do instrumento.

A autora do estudo sobre corpo e corporeidade fez uma análise de dissertações e teses defendidas no período de 2010 a 2016, produzidas em universidades públicas e privadas das diversas regiões do Brasil. Nessa busca, foram encontrados 10 estudos, sendo 8 dissertações e 2 teses. Os trabalhos revelaram que alguns profissionais se esfor- 
çam para buscar estratégias e elaborar diversidade de conteúdos que viabilizam a questão da corporeidade visando à prática pedagógica rica em possibilidades. Os profissionais têm ciência da importância de trabalhar o corpo e a corporeidade na Educação Infantil, porém muitas escolas deixam de oferecer espaços e tempos de liberdade, espaços integrados de vivências e experiências criativas e lúdicas, para que a criança possa desenvolver as múltiplas linguagens, entre elas a corporal.

Esta pesquisa revela novamente o quanto os corpos são dóceis na Educação Infantil, basta ver o número inexpressivo de estudo encontrados pela autora. O resultado nos leva a afirmar que a contenção dos corpos infantis ainda é a premissa na escola da primeira infância.

Em relação aos estudos referentes à formação continuada, os pesquisadores afirmam que esse é o momento propício para trocas de informações e de saberes, no qual os professores podem compartilhar alegrias, dúvidas e anseios, além de se autoanalisarem em relação às próprias práticas e de colaborarem mutuamente.

Esses estudos vêm ao encontro do que já foi dito anteriormente, da potência da formação continuada, porém insistimos em dizer que não podemos deixar as professoras na zona de conforto, a mudança tem de partir delas, dos próprios estudos e questionamentos.

As temáticas voltadas à gestão versaram sobre: gestão democrática; papel da gestão, de professoras e de funcionários no que se refere à ressignificação das práticas e mudança na cultura, execução de planejamento com a ajuda das crianças.

Os trabalhos realizados diretamente com a equipe gestora apontam que a gestão escolar, quando assume a liderança pedagógica, mobiliza a equipe de professoras para a mudança nas práticas antecipatórias e escolarizadas presentes na cultura escolar, desnaturaliza a cultura da escola e provoca reflexões acerca das concepções de infância, criança e de proposta pedagógica desenvolvidas, qualificando o plano de formação da equipe a fim de promover avanços mais significativos nas mudanças das práticas, porém não deixa de haver contradições no que se refere às concepções de creche, Educação Infantil, gestão escolar, formação continuada em serviço e valorização profissional.
Um estudo revelou, numa mesma escola, por parte dos/das professores/as diferentes concepções de planejamento mostrando-se em grande parte como um instrumento burocrático. Portanto, a intervenção da equipe gestora precisa ser intensificada no que diz respeito ao assunto, principalmente tendo um trabalho de formação continuada em horário de serviço que permita a continuidade de discussão do tema planejamento e rotina.

Um dos trabalhos apontou que execução de um planejamento democrático e participativo com crianças de creche é possível, para isso é necessário que o/a professor/a conceba a criança como um sujeito capaz e de direitos, que também produz cultura, realizando ações de participação das crianças como protagonistas.

Diante do exposto, o dado mais relevante e que, infelizmente, não é novidade está voltado para a fragilidade da formação inicial dos/as professores/as; no nosso caso, o curso de Pedagogia. Tal dado continua reafirmando a pesquisa realizada por Gatti (2009), a qual examinou 71 cursos de graduação presenciais em Pedagogia, distribuídos em todo o país.

A autora ressalta que o currículo desse curso é fragmentado, contém um conjunto disciplinar diverso, ou seja, não há articulação curricular entre as disciplinas; é muito teórico, portanto, "A escola, enquanto instituição social e de ensino, é elemento quase ausente nas ementas, o que leva a pensar numa formação de caráter mais abstrato e pouco integrado ao contexto concreto onde o profissional-professor vai atuar" (GATTI, 2009, p. 55). Dessa forma, segundo a autora, o curso de Pedagogia, da forma como se estrutura atualmente, não auxilia na formação de professores que irão lecionar na Educação Infantil e no Ensino Fundamental I.

No ano de 2019, a mesma autora lança o relatório Professores do Brasil: novos cenários de formação em parceria com as pesquisadoras Elba Siqueira de Sá Barretto, Marli Eliza Dalmazo Afonso de André e Patrícia Cristina Albieri de Almeida o qual, infelizmente, aponta que pouca mudança houve em relação aos dados de dez anos atrás. Lamentável. Em relação aos alunos que frequentam as licenciaturas, as autoras ressaltam: 
[...] a maioria provém do ensino médio geral, portanto, sem nenhuma iniciação em aspectos da área educacional. Entretanto, nos cursos de pedagogia, diplomados em magistério ainda constituem $1 / 4$ dos concluintes desse curso. Observa-se ainda um aumento significativo de alunos da escola pública nas licenciaturas o que leva à constatação que eles se tornaram cursos "populares", à medida que os seus alunos passaram a efetivamente representar as camadas majoritárias da população (GATTI et al;, 2019, p. 309).

O segundo elemento a nos chamar atenção é que a maioria dos autores aponta o quanto a formação continuada em serviço se faz necessária, portanto, entendem os horários de reuniões como propulsores para a ressignificação da prática escolar por meio da ação-reflexão-ação.

O terceiro dado importante é que dos 24 trabalhos, 20 discutiram questões relacionadas às práticas pedagógicas e somente quatro a gestão escolar e o planejamento em conjunto com gestores e professores. Esse fato nos leva a inferir que os mestrandos/professores, mesmo sendo gestores, estão preocupados em minimizar os problemas encontrados nos fazeres cotidianos das escolas, principalmente ao que se refere à aprendizagem das crianças.

\section{CONSIDERAÇÕES FINAIS}

Constatamos que no Programa de Mestrado Profissional pesquisado, das 142 dissertações defendidas em seu primeiro quadriênio de existência, apenas 24 discutiram a Educação Infantil, fato este que aponta a inexpressividade de estudos sobre essa etapa de ensino até o momento; porém, tem havido, nesse Programa, um aumento de pesquisadores/as que buscam discutir a Educação Infantil.

As pesquisas apresentadas divergiram nas temáticas que, no nosso entendimento, é bastante salutar, uma vez que essas especificidades de estudos apontaram como foi realizado o trabalho com os pequenos, as concepções dos/as professores/as sobre as temáticas estudadas e, principalmente, como foi conduzida a formação em serviço.

Observamos que, das 24 pesquisas realizadas na e sobre a Educação Infantil, em 20 delas os/ as pesquisadores/as utilizaram a pesquisaintervenção na perspectiva da ação-reflexãoação, para nós, fundamental em um Programa de Mestrado Profissional, uma vez que esse modelo metodológico permite que os/as professores/as reflitam sobre a prática pedagógica em espaços formativos para que possam ressignificá-la a partir dos questionamentos e aprendizagens adquiridos com seus pares.

A maioria das pesquisas indicou que as escolas da infância ainda se utilizam, ora de propostas assistencialistas, ora de propostas preparatórias para o ensino fundamental e não vislumbram as especificidades da infância, afastando as crianças de possibilidades profícuas de aprendizagem; as práticas, na maioria das vezes, não dialogam com o que é proposto pelos documentos oficiais. Não estamos dizendo que eles têm de ser executados tal como se apresentam; merecem críticas, porém muitas propostas neles contidas vêm ao encontro de uma pedagogia da primeira infância renovada, que deve ser analisada de acordo com os diferentes contextos e situações.

Tal fato pode estar associado à falha na formação inicial dos/as professores/as, desvinculando a teoria da prática, conforme apontado nos trabaIhos e na concepção de criança ainda vigente: ser passivo, não capaz de construir cultura, sem voz e sem vez. O corpo ainda se encontra inerte na escola da primeira infância.

Diante disso, reafirmamos, assim como os/ as autores/as das pesquisas apresentadas, o papel fundamental da equipe gestora na condução da formação em serviço, uma vez que, nos estudos analisados, essa formação minimizou os problemas e as dificuldades encontrados pelos/as professores/as no dia a dia escolar. Porém, para que a formação continuada em serviço seja eficaz, faz-se necessário que a equipe gestora se comprometa diante do grupo de professores/as discutindo questões emergentes de cada realidade, pautando -se em referenciais teóricos consistentes que possam dar respostas para os problemas enfrentados, por meio da reflexão e da crítica constante.

Os/As professores/as têm de continuar se empenhando, a fim de que possam eliminar o ranço assistencialista ainda existente na Educação In- 
fantil, principalmente com as crianças de 0 a 3 anos, a escolarização precoce com as crianças de 4 e 5 anos e se responsabilizarem com um trabalho que vislumbre uma concepção de criança que as entende como seres ativos do processo de aprendizagem, construtoras de cultura e de saberes, que respeite as especificidades da infância. Além disso, devem estar abertos ao novo, sem que o antigo seja menosprezado, mas ressignificado.

Vale lembrar que, nas publicações anuais do nosso grupo de pesquisa, a maioria das pesquisas mencionadas neste artigo foram publicizadas pelos/ as pesquisadores/as, pois entendemos que as práticas docentes e de gestão, as dificuldades e os acertos enfrentados precisam ser de conhecimento do professorado a fim de que possam perceber que, em muitas situações, não se encontram sozinhos, e que é possível, dentro dos limites e das possibilidades de cada escola, transformar o cotidiano.

Estudar a Educação Infantil, principalmente a creche, merece destaque por parte dos/as pesquisadores/as, pois se trata de uma etapa da educação básica ainda negligenciada, na qual os/as professores/as são menos valorizados em relação aos dos demais ciclos, a identidade não está clara, o cuidar e o educar ainda se encontram dissociados; as práticas pedagógicas são desvinculadas da realidade das crianças, entre outros aspectos.

Salientamos que estamos realizando um estudo em profundidade dos trabalhos desenvolvidos nos 50 Programas de Mestrado Profissional em Educação existentes no Brasil (até final de 2019) sobre e na Educação Infantil nas diferentes regiões do país, para que possamos ter uma ideia mais apurada da quantidade de pesquisas defendidas, as respectivas temáticas e resultados obtidos.

Intencionamos verificar se os demais trabaIhos apontam os resultados que nos chamaram mais atenção nos 24 estudos aqui apresentados, a saber: concepção de criança das instituições da primeira infância; fragilidade da formação inicial com foco nos cursos de Pedagogia; contribuição da formação continuada em serviço; pesquisa-intervenção como recurso dos/as pesquisadores/as e, acima de tudo, a criança como protagonista no espaço escolar.

\section{REFERÊNCIAS}

BRASIL. Ministério da Educação. MEC institui modalidade de doutorado profissional. Disponível em: http://www.capes.gov.br/sala-de-imprensa/ noticias/8328-portaria-institui-doutoradoprofissional. Acesso em: 10 de julho de 2020.

DAMIANI, M. F. Sobre pesquisas do tipo intervenção. In: ENCONTRO NACIONAL DE DIDÁTICAS E PRÁTICAS DE ENSINO, 16., 2012, Campinas. Anais eletrônicos... Campinas: Unicamp, 2012. Disponível em: http:// infoteca.inf.br/endipe/smarty/templates/ arquivos_template/upload_arquivos/acervo/ docs/2345b.pdf. Acesso em: 15 agosto 2020.

FOUCAULT, M. Vigiar e punir: história da violência nas prisões. 37. ed. Rio de Janeiro: Vozes, 2009.

FREIRE, P. Pedagogia do oprimido. 32.ed. Rio de Janeiro: Paz e Terra, 2002.

GABRE, S. Contribuições da pesquisa-intervenção na construção de um projeto educativo no museu de arte: pensando a mediação cultural para a pequena infância In: SEMINÁRIO DE PESQUISA EM EDUCAÇÃO DA REGIÃO SUL, 9., 2012, Caxias do Sul. Anais eletrônicos... Caxias do Sul: Anped, 2012. Disponível em: http://www.ucs.br/etc/ conferencias/index.php/anpedsul/9anpedsul/paper/ viewFile/2083/764. Acesso em: 15 agosto de 2020.

\section{GATTI, B. A.; NUNES, M. M. R. (org.). Formação de} professores para o ensino fundamental: estudo de currículos das licenciaturas em pedagogia, língua portuguesa, matemática e ciências biológicas. São Paulo: FCC/DPE, 2009.

GATTI. B. A et al. Professores do Brasil: novos cenários de formação. Brasília: UNESCO, 2019, 351 p. Disponível em: https://www.fcc.org.br/fcc/wpcontent/uploads/2019/05/Livro_Professores DoBrasil.pdf. Acesso em: 19 de agosto de 2020. 